
\title{
25 Research Square \\ DUOX2 is a Generator of ROS in the Ovary and a Potential Mediator of Ovulation
}

\section{Gil M Yerushalmi}

Shamir Medical Center (formerly Assaf Harofeh Medical Center) https://orcid.org/0000-0002-44517664

\section{Yuval Yung}

Chaim Sheba Medical Center: Sheba Medical Center at Tel Hashomer

\section{Oranit Saiagh Dayan}

Chaim Sheba Medical Center: Sheba Medical Center at Tel Hashomer

\section{Ettie Maman}

Chaim Sheba Medical Center: Sheba Medical Center at Tel Hashomer

\section{Sarit Avraham}

Shamir Medical Center: Yitzhak Shamir Medical Center Assaf Harofeh

\section{Alon Kedem}

Shamir Medical Center: Yitzhak Shamir Medical Center Assaf Harofeh

Ariel Hourvitz ( $\square$ arielho@shamir.gov.il)

Shamir Medical Center: Yitzhak Shamir Medical Center Assaf Harofeh

\section{Research}

Keywords: DUOX2, reactive oxygen species, ovary, ovulation

Posted Date: November 19th, 2020

DOI: https://doi.org/10.21203/rs.3.rs-108469/v1

License: (c) (i) This work is licensed under a Creative Commons Attribution 4.0 International License.

Read Full License 


\section{Abstract}

Background: Ovulation is triggered by the preovulatory surge of the pituitary luteinizing hormone (LH). LH/hCG induction of reactive oxygen species (ROS) is required for successful ovulation. $\mathrm{H}_{2} \mathrm{O}_{2}$, one of ROS species, was shown to fully mimic the effect of LH/hCG in mice ovulation. However, the molecular process that generates $\mathrm{H}_{2} \mathrm{O}_{2}$ in the ovary during ovulation remains largely unknown. DUOX2, a member of the NOX/DUOX family of NADPH oxidase, is capable of generating $\mathrm{H}_{2} \mathrm{O}_{2}$.

Results: Using global transcriptome RNAseq, we identified that DUOX2 is one of the transcripts that was markedly upregulated in granulosa cells during ovulation. Treatment with human chorionic gonadotropin (hCG), an ovulatory trigger, significantly increases the expression of DUOX2 mRNA and protein in human GCs both in vivo and in vitro. hCG-induced up-regulation of DUOX2 is mediated by the CAMP-PKA and the PKC pathway. A functional test reveals that DUOX2 chemical inhibitor, Diphenyleneiodonium (DPI), an NADPH oxidase inhibitor, decreased $\mathrm{H}_{2} \mathrm{O}_{2}$ levels in MGCs (Mural Granulosa Cells) treated with hCG. The inhibition of $\mathrm{H}_{2} \mathrm{O}_{2}$ by DPI suggests that DUOX2 activity is required for hCG-induced elevation of extracellular $\mathrm{H}_{2} \mathrm{O}_{2}$ in MGCs. In vivo treatment of mice with DPI significantly decreases the number of ovulated oocytes and markedly attenuates the expression of key ovulatory genes. These results support the putative role of DUOX2 in ovulation.

Conclusions: DUOX2 is a ROS generator during the ovulatory process and is involved in the LH/hCGinduced signaling cascades leading to ovulation. Treatment with DUOX2 inhibitors may affect late folliculogenesis and ovulation and thus may serve for fertility control.

\section{Background}

Reactive oxygen species (ROS) are oxygen-derived small molecules, including superoxide $\left(\mathrm{O}_{2} \cdot\right)$, hydroxyl, peroxyl $\left(\mathrm{RO}_{2}{ }^{\circ}\right)$, and alkoxyl ( $\left.\mathrm{RO}\right)$ and certain nonradicals that are either oxidizing agents and/or are easily converted into radicals, such as hydrogen peroxide $\left(\mathrm{H}_{2} \mathrm{O}_{2}\right)(1)$. The ROS are involved in a spectrum of functions including hormone biosynthesis, cell signaling, aging and microbial killing (2). Studies in mouse model revealed that ROS have a role in ovulation (3). In the corpus luteum, they are involved in steroid production (4). ROS dysregulation may lead to oxidative stress which has a detrimental effect on fertility including impaired oocyte quality, follicular atresia and reduced pregnancy rate in $\operatorname{IVF}(5,6)$.

Our laboratory has undertaken to systematically identify ovulation-associated genes $(7,8)$. Differentially expressed candidate genes $(n=1746)$ were identified by comparing the transcriptome of compact cumulus cells (CCs) from germinal vesicle cumulus oocyte complexes (COCs) obtained from patients undergoing in vitro maturation (IVM) procedures (CCGV), and expanded CCs from metaphase 2 (CCM2) COCs were obtained from patients undergoing IVF/ICSI. The differentially expressed genes identified likely serve as regulators of ovulation, cumulus expansion, and/or oocyte maturation. 
The analysis of the resultant transcriptome database revealed that the NADPH oxidase DUOX2 exhibit a 602-fold increase in expanded CCs (CCM2) compared to immature CCs (CCGV). DUOX2 is a major source of ROS (9). Other NADPH oxidases identified in cumulus granulosa cells include DUOX1 which exhibited a 14-fold increase in CCM2s. NOX4 and NOX5 were identified at negligible levels. Other NOX genes were not expressed.

Prompted by the observation that DUOX2 constitutes a highly expressed periovulatory transcript, we set out to investigate the physiological role of this key NADPH oxidase in the ovulatory process.

\section{Results}

\section{DUOX2 expression in human granulosa cells in vivo.}

Illumina-based RNA-sequencing (RNAseq) was carried out on RNA extracted from compact (CCGV) and expanded (CCM2) cumulus cells and sequence counts were used to assess gene expression (8). As shown in Fig. $1 \mathrm{~A}$, the in vivo expression of DUOX2 transcripts in CCs of expanded post-ovulatory MII COCs after in vitro fertilization (IVF) was 602-fold higher $(\mathrm{p}<0.0001)$ as compared with CCs of compact GV COCs obtained during in vitro maturation (IVM). DUOX1 transcript was induced 14-fold in CCs of expanded post-ovulatory MII COCs but NOX1-5 were below threshold detection level.

In humans, during follicular antrum formation, GCs produced two distinct lineages; Mural GCs that line the follicular wall and cumulus GC (CGC) that surround the oocyte (10). We compared the expression levels of DUOX2 mRNA in MGCs and CGC by qPCR. MGCs and CGCs were obtained from large preovulatory follicles (>17 mm) during the IVF procedure. As shown in Fig. 1B, CGCs expressed significantly higher (2.6-fold) levels of DUOX2 mRNA relative to MGCs $(p=0.018)$.

The impact of the oocyte-cumulus cell relationships on both maturation and fertilization capacity has been well-established $(11,12)$. CGCs reflect the characteristics of the oocyte, providing a noninvasive means to assess oocyte quality. Several researchers have reported that gene expressions of CGCs could be used as a tool to predict oocyte competence or embryo development $(13,14)$. To reveal whether DUOX2 is involved in oocyte maturation processes, we evaluated the expression of DUOX2 in CGCs isolated from GV and M2 oocytes retrieved during IVF procedures.

As shown (Fig. 1C) DUOX2 was expressed in CGCs isolated from mature M2 COCs at higher levels than in immature GV COCs $(p=0.015)$.

DUOX2 expression pattern in vitro and in vivo during the ovulation process.

The increase of DUOX2 in our library suggests that it is an hCG target gene. To confirm our in vivo observations, we employ an in vitro system of cultured MGCs. Luteinized MGCs obtained from IVF procedure cultured for 4 days with a daily medium exchange to transform them into "early non-luteinized like MGCs" (15). MGCs were further cultured without hCG (control) or stimulated with $1 \mathrm{U} / \mathrm{ml} \mathrm{hCG}$ for $24 \mathrm{~h}$. The induction of DUOX2 protein by hCG was detected by western blot (Fig. 1D) and 
immunofluorescence assay (Fig. 1E). Western blot quantification using ImageJ software found that hCG induces DUOX2 protein significantly (Fig. 1D, $p=0.013$ ), confirming DUOX2 as an hCG-induced gene.

The in vitro system of cultured MGCs time response expression pattern following hCG stimulation may hint for the role of DUOX2 in the ovary. After hCG stimulation, the cultured MGCs cells were harvested at $0,3,6,12,24$ and $36 \mathrm{~h}$ later. DUOX2 mRNA was observed to be upregulated in hCG-treated cells, peaking at $12 \mathrm{~h}$ after hCG treatment (Fig. 1F) and returning to basal levels at $36 \mathrm{~h}$ post-hCG treatment. We also examined the ovarian DUOX2 expression pattern in vivo using the superovulation mouse model. PMSG treated mice were injected with hCG and harvested after $0,3,6,9$, and $12 \mathrm{~h}$. The increase in DUOX2 mRNA expression was observed at $9 \mathrm{~h}$ and reached maximal levels at 12 hours after $\mathrm{hCG}$ injection just before ovulation (Fig. 1G).

\section{Regulation of DUOX2 expression in cultured human mural granulosa cells: intracellular signaling pathways}

The LHCGR activates multiple signaling pathways, including protein kinase A (PKA) (16) and protein kinase $C$ (PKC) (17). To determine the role of these signaling systems in the hCG-dependent up-regulation of DUOX2 expression, cultured MGCs were treated with FSK (an activator of adenylyl cyclase that in turn leads to the activation of PKA) or PMA (a PKC activator) for $24 \mathrm{~h}$. As shown in Fig. 2, FSK $(10 \mu \mathrm{M})$ significantly increased DUOX2 transcripts in MGCs 10.2-fold compared to control $(p<0.001$, Fig. $2 A)$. The effect was abolished following pre-treatment with $\mathrm{H} 89$ for 1 hour (a selective PKA inhibitor; $10 \mu \mathrm{M}, \mathrm{p}<$ 0.001). PMA (20 nM) treatment significantly increased DUOX2 transcripts in MGCs $4.1-\mathrm{fold}$, compared to control ( $p=0.042$, Fig. $2 B)$.

In addition to the PKA and PKC pathways other intracellular signaling cascades, such as the phosphatidylinositol 3-kinase (PI3-K)/Akt pathway may also be involved in the signal transduction of DUOX2. To examine the role of these signaling pathways in the regulation of DUOX2 expression, MGCs were pretreated for 30 min with pharmacological inhibitors for PI3K (10 $\mu \mathrm{M}$ LY294002) pathways, followed by a $24 \mathrm{~h}$ treatment with $1 \mathrm{U} / \mathrm{ml} \mathrm{hCG}$. The results show that LY294002 (Fig. 4C) did not affect the hCG induction of DUOX2 expression.

In summary, our results indicate that the PKA and PKC pathways are the main mediators of the $\mathrm{LH} / \mathrm{hCG}$ induction of DUOX2 up-regulation.

\section{Assessment of the role of DUOX2 in hCG-induced $\mathrm{H}_{2} \mathrm{O}_{2}$ generation in cultured human mural GCs.}

To confirm the role of DUOX2 in the generation of $\mathrm{H}_{2} \mathrm{O}_{2}$ in the follicle, MGCs were cultured without hCG (control), hCG or with hCG + DPI (a known non-specific DUOX2 inhibitor) for $10 \mathrm{~h}$ and the $\mathrm{H}_{2} \mathrm{O}_{2}$ levels were quantified (Fig. 2D).

$\mathrm{H}_{2} \mathrm{O}_{2}$ levels were 2.1-fold higher in MGC's that were treated with $\mathrm{hCG}$ than in control. The treatment with DPI inhibited $\mathrm{H}_{2} \mathrm{O}_{2}$ generation by about $96 \%$. The inhibition of $\mathrm{H}_{2} \mathrm{O}_{2}$ by DUOX2 inhibitor DPI suggests that 
DUOX2 activity is a source for the hCG-induced elevation of extracellular $\mathrm{H}_{2} \mathrm{O}_{2}$ in granulosa cells.

\section{The effect of DUOX2 blockade on ovulation in vivo.}

To evaluate the physiological role of DUOX2 in the ovulatory process, we tested the effect of DPI on ovulation in mice treated by the PMSG/hCG superovulation protocol. As shown in Table 1, 100\% of the mice treated with hCG ovulated, releasing an average of 54.3 oocytes. Concurrent injection of hCG and 5 or $7 \mathrm{mg} / \mathrm{kg}$ of DPI decreased the number of ovulated oocytes of the mice with a mean of 43.7 and 28.3 oocytes per ovulating mouse respectively, which represent $19.5 \%$ and $47.8 \%$ respectively, reduction in ovulation efficiency compared to hCG ( $p=0.0477$ and $p=0.0001$ respectively).

Table 1

The effect of hCG and dose-response of DPI on ovulation in a superovulation mouse model.

\begin{tabular}{|llll|}
\hline Treatment & $\begin{array}{l}\text { No. of ovulation mice / no. of } \\
\text { treated (\%) }\end{array}$ & $\begin{array}{l}\text { No. of Oocytes } \\
\text { (means } \pm \text { SEM) }\end{array}$ & $\begin{array}{l}\text { Range of oocyte } \\
\text { numbers in } \\
\text { ovulating mice }\end{array}$ \\
\hline hCG & $23 / 23(100)$ & $54.3 \pm 4.7$ & $31-111$ \\
\hline $\begin{array}{l}\text { hCG }+5 \text { mg/kg } \\
\text { DPI }\end{array}$ & $22 / 24(91.7)$ & $\begin{array}{l}43.7 \pm 4.6(p= \\
0.0477)\end{array}$ & $0-82$ \\
\hline $\begin{array}{l}\text { hCG }+7 \mathbf{~ m g} / \mathbf{k g} \\
\text { DPI }\end{array}$ & $19 / 21(90.5)$ & $\begin{array}{l}28.3 \pm 4.6(p= \\
0.0001)\end{array}$ & $0-64$ \\
\hline
\end{tabular}

These results show that DPI is partially inhibiting ovulation in mice suggesting a role of DUOX2 in ovulation.

To further validate the ovulation-blocking activity of DPI, we performed a histological examination of ovaries removed from the vehicle- or DPI ( $7 \mathrm{mg} / \mathrm{kg}$ )-treated mice at 16 hours after hCG administration (Fig. 3C). PMSG treatment led to the development of numerous preovulatory follicles (Fig. 3C I and 3C II). Removal of the ovaries from hCG-treated mice 16 hours after the administration of hCG revealed numerous early corpora luteal (Fig. 3C III and 3C IV). In contrast, the ovaries harvested from mice receiving hCG plus DPI (Fig. $3 \mathrm{C} \mathrm{V}$ and $3 \mathrm{C} \mathrm{VI)}$ ) contained unruptured preovulatory follicles replete with intact MGCs and thick multilayered follicular walls, with no signs of impending ovulation, resembling ovaries obtained from mice treated with PMSG alone. These histological results further demonstrate that the treatment of mice with a DUOX2 inhibitor inhibits ovulation, confirming the putative role of DUOX2 in ovulation.

\section{Effect of inhibition of DUOX2 on the levels genes that regulate ovulation and corpus luteum function}

To characterize the ovulation-inhibiting effect of DUOX2 at the molecular level, we evaluated the effect of treatment with DPI on LHCGR-dependent activities. Specifically, we set out to study key representative genes of the ovulatory cascade. These genes included those involved in oocyte maturation (Areg, Ereg) 
$(18,19)$, progesterone receptor signaling $(P g r)(20)$, cumulus expansion (Tnfaip6) (21), and steroidogenesis (Star) (22).

As shown in Fig. 3A, treatment with $7 \mathrm{mg} / \mathrm{kg}$ DPI inhibitor and hCG; significantly inhibited the expression of all genes examined compared to hCG only.

To assess the corpus luteum function, we measured serum progesterone concentration in PMSGprimed/hCG-triggered mice in the absence or presence of $7 \mathrm{mg} / \mathrm{kg}$ of DPI. Concurrent treatment with DPI did not affect serum progesterone levels compared to hCG only (Fig. 3B).

\section{Discussion}

The ovary is a metabolically active organ and generates reactive oxygen species (ROS) and reactive nitrogen species (RNS) on an extraordinary scale during various physiological processes including ovulation and control of oocyte maturation. In mammals, free radicals are generated by $\mathrm{H}_{2} \mathrm{O}_{2}$ generators enzymes and as by-products of normal cellular metabolism. Free radicals serve as key signal molecules in various physiological and pathological processes.

In vivo studies in combination with ex vivo and molecular analyses were used to provide the evidence that reactive oxygen species present in the preovulatory ovarian follicles are essential for the ovulatory process (3). However, knowledge of the molecular process that provides reactive oxygen species in the ovary and during the ovulatory process is only partial. Earlier reports show that Nox/Duox NADPH oxidases are considered the primary, regulated sources of reactive oxygen species (ROS). These enzymes are expressed in diverse cells and tissues, and their products are essential in several physiological settings (23).

Ovulation is a key event in mammalian female reproduction, therefore the discovery of key players involved in this process is extremely important. Our laboratory applied the RNA sequencing method to systematically isolate genes with an ovulation-selective pattern of expression (8). DUOX2 was among the highly upregulated genes in our library. Taking into account the importance of reactive oxygen species for the ovulatory process (3), DUOX2 was selected for further study of its ovulation-associated expression and function.

Duox enzymes were initially identified as $\mathrm{H}_{2} \mathrm{O}_{2}$ sources involved in thyroperoxidase mediated organification of iodide during thyroid hormone biosynthesis $(24,25)$. Duox enzymes are also detected in exocrine (salivary) glands and on mucosal surfaces (airways, gastrointestinal tract), where they were proposed to support the antimicrobial activity of lactoperoxidase (23). Whereas their producer in the ovary and its contribution to the regulation of ovulatory cascade remains largely unknown.

In vitro studies have shown that $\mathrm{LH}$ surge induces the generation of ROS that is required for successful ovulation; Moreover, $\mathrm{H}_{2} \mathrm{O}_{2}$ was shown to fully mimic the effect of $\mathrm{LH}(3)$. 
$\mathrm{H}_{2} \mathrm{O}_{2}$ levels were induced in MGCs that were treated with hCG (26). DPI treatment inhibited $\mathrm{H}_{2} \mathrm{O}_{2}$

generation induced by hCG. The inhibition of $\mathrm{H}_{2} \mathrm{O}_{2}$ by DUOX2 inhibitor DPI suggests that DUOX2 activity is required for $\mathrm{hCG}$ elevation of extracellular $\mathrm{H}_{2} \mathrm{O}_{2}$ in granulosa cells. DPI is not a specific DUOX2 inhibitor and has other NADPH oxidase targets including NOX1, NOX2, NOX3, NOX4, NOX5, DUOX1, and DUOX2. However, except DUOX2, of the NADPH oxidase family only DUOX1 was present and upregulated in our library of ovulation associated genes (Fig. 1A) but at much lower expression than DUOX2 (40-fold), suggesting that the inhibitory effect of DPI is primarily mediated through DUOX2. Further studies using DUOX2 conditional-knockdown technology may confirm these results.

Recently, it was suggested that NOX4 is a major producer of $\mathrm{H}_{2} \mathrm{O}_{2}$ in human GCs in vitro (27). They were able to show that NOX1/4 inhibitor (GKT137831) shows a partial decrease in $\mathrm{H}_{2} \mathrm{O}_{2}$ release in culture MGCs, suggesting the function of NOX1/4 as a mediator of $\mathrm{H}_{2} \mathrm{O}_{2}$ in the ovary. However, in accordance with our findings, they show that hCG did not affect levels of NOX4 and NOX5, but did significantly increased DUOX1 and DUOX2. Therefore, we cannot rule out that NOX4 is a source for $\mathrm{H}_{2} \mathrm{O}_{2}$ in the ovary but the fact that NOX4 levels are not under the control of FSH or LH/hCG in GCs, does not support their potential role in the ovulatory process, which is in agreement with our results.

\section{Conclusions}

In summary, our study reveals DUOX2 as an important gene in the ovulatory process. We showed that DUOX2 is upregulated in CCs of hCG treated GCs and that the CAMP-PKA pathway but not by the PKC pathway mediates DUOX2 regulation. Moreover, we have demonstrated DUOX2 functions as an $\mathrm{H}_{2} \mathrm{O}_{2}$ generator in the ovary. These findings were further substantiated by in vivo assays. The effect of DPI, a DUOX2 chemical inhibitor, on mice ovulation show a dose-dependent manner partial blocking effect on ovulation and resulted from an inhibition of the hCG-induced ovulatory cascade in mice, including oocyte maturation and follicular rupture but not the steroidogenic pathway. All these findings mark DUOX2 as a novel ovulatory gene, filling the gap between hCG induction of ROS/ $\mathrm{H}_{2} \mathrm{O}_{2}$ and ovulation.

A better understanding of the precise mechanism of $\mathrm{H}_{2} \mathrm{O}_{2}$ generation inside the follicular microenvironment during final follicular maturation by DUOX2 may enable us to define new targets for improvement of in vitro maturation (IVM) media, fertility control, and contraception.

\section{Methods}

\section{Patients}

MGCs samples aspirated during IVF procedures in IVF unit in the Sheba Medical Hospital were used. The study was approved by the local Institutional Review Board (IRB) committee of Chaim Sheba Medical Center, Tel Hashomer (ethical approval number SMC-11-8707 and SMC-12-9342). Written informed consent was obtained from each patient who provided samples. All experiments involving mice were 
conducted in compliance with the principles of the National Research Council (NRC) and were approved by the institutional animal care and use committee (IACUC) \#919/14/ANIM.

A total of 33 women were included with an average age of $32 \pm 4$ (mean \pm SD), BMI $21.5 \pm 2.3$, oocyte retrieved $10 \pm 3$. All patients were treated with antagonist protocols to get consistent results and avoid the effect of different protocols (see below)

\section{In Vitro Fertilization (IVF) Protocol}

Patients underwent ovarian stimulation using a GnRH antagonist protocol (Cetrorelix; Merck Serono, Darmstadt). Ovarian stimulation was performed using a daily subcutaneous dose of human recombinant FSH (either Gonal-F; Merck Serono, an affiliate of Merck KGaA, Darmstadt, Germany or Puregon; Schering Plough, North Wales PA) which was commenced on the third day of the menstrual cycle. After 5 days of stimulation, the women received human menopausal gonadotrophin (hMG; Menopur, Ferring, Switzerland). The initial dose used was dependent upon age, body mass index and prior IVF treatment history. When three or more follicles exceeded $18 \mathrm{~mm}$ in diameter, $250 \mu \mathrm{g}$ of hCG (Ovitrelle; Merck Serono) was administered to trigger ovulation. Oocyte retrieval was performed $36 \mathrm{~h}$ following hCG triggering by transvaginal ultrasound-guided needle aspiration.

\section{Cumulus granulosa cell collection}

After COC retrieval, CCs of each oocyte were removed with the use of hyaluronidase (SAGE, Trumbull, CT, USA) and a glass denudation pipette (Swemed, Billdal, Sweden). The CGCs were washed in PhosphateBuffered Saline (PBS) and centrifuged at $5000 \times \mathrm{g}$ for 5 minutes at room temperature. The resulting pellets were stored at $-80^{\circ} \mathrm{C}$ until RNA isolation. CCs of individual oocytes were classified as per the corresponding oocyte maturation stage: CCs from GV oocytes (CCGV) and CCs from MIl oocytes (CCM2). CCs obtained from individual oocytes were collected from individual subjects were pooled to generate a single replicate ( $n=3-4$ different subjects). Each experiment was performed at least three times.

\section{Mural Granulosa Cell Collection and Grouping}

MGCs were collected from the aspirated follicular fluid (Follicles size $>=17 \mathrm{~mm}$ ) and re-suspended in a phosphate-buffered solution (PBS; Sigma-Aldrich-Aldrich, St Louis, MO, USA). After allowing the cells to settle by gravity for a few minutes, the top portion of the medium was repeatedly re-suspended and aspirated until such time that the medium proved clear. The cells were then centrifuged at $1000 \mathrm{rpm}$ for 5 minutes at room temperature. The resulting pellets were stored at $-80^{\circ} \mathrm{C}$ until RNA isolation. MGCs from 3 different subjects were pooled to generate a single replicate.

\section{Mural Granulosa Cell Culture}

MGCs were collected as described above and placed on a percoll gradient and centrifuge at 3000 RPM for $15 \mathrm{~min}$. The MGCs were collected and washed with PBS, counted and plated in 24-well plates at a density of 100,000 cells/well, and incubated at $37^{\circ} \mathrm{C}$ in a humidified atmosphere with $5 \% \mathrm{CO} 2$ in the air. 
The cells were cultured for 4 days with a daily medium replacement before hCG triggering as previously described (28). For signaling study, MGCs were pre-treated with H89 $(10 \mu \mathrm{M})$ or LY $294002(10 \mu \mathrm{M})$ for 30 minutes and then stimulated with either hCG $(1 \mathrm{U} / \mathrm{ml})$ or forskolin (FSK, $10 \mu \mathrm{M})$ or Phorbol-12-Myristate13-AcetateXYZ (PMA, $10 \mu \mathrm{M}$ ) for an additional 24 hours (all chemicals from LC Laboratories, Woburn, MA, USA).

\section{RNA Extraction and qPCR}

RNA extraction and qPCR. Total RNA was extracted from MGCs or CCs using a Mini/Micro RNA Isolation I kit (Zymo Research, CA, USA) according to the manufacturer's instructions. RNA purity and concentration were assessed using a NanoDrop spectrophotometer (NanoDrop 2000C, Thermo Scientific Waltham, MA, USA). Total RNA (25ng) from each sample was used for CDNA synthesis by a high capacity reverse transcription kit (Applied Biosystems, Carlsbad, CA, USA) according to the manufacturer's instructions in a $10 \mu$ l total volume reaction. mRNA levels were analyzed by real-time PCR using the StepOnePlus realtime PCR system (Applied Biosystems). The real-time PCR mix contained $1 \mu \mathrm{l}$ of cDNA, fast SYBR Green Master Mix (Applied Biosystems), and specific primers for DUOX2 or another gene of interest and $\beta$-actin (housekeeping gene) in a total volume of $10 \mu \mathrm{l}$. Cycling parameters were: $1 \mathrm{cycle}$ at $95^{\circ} \mathrm{C}$ for 20 seconds and 40 cycles each at $95^{\circ} \mathrm{C}$ for 3 seconds and $60^{\circ} \mathrm{C}$ for 30 seconds. A melting curve analysis was performed at the end of each run to ensure a single amplicon. All samples were run in duplicates. Analysis of the qPCR results was carried out with StepOne software. Relative gene expression was calculated using the delta-delta Ct method. Details of the primers used are shown in Table S1.

\section{Western blot}

Cells harvested using $0.5 \mathrm{~mL}$ PBS and pelleted. Cell pellets were lysed in TNE buffer ( $50 \mathrm{mM}$ Tris- $\mathrm{HCl}, \mathrm{pH}$ 8.0, $250 \mathrm{mM} \mathrm{NaCl}, 2 \mathrm{mM}$ EDTA, 1\% NP-40, Sigma Aldrich St Louis Mo) and protease inhibitor cocktail (Sigma-Aldrich, St. Louis, MO), vortexed and incubated for $10 \mathrm{~min}$ on ice before removal of nuclei and debris by centrifugation. Aliquots of the clarified supernatants were used to determine protein concentration. Protein concentration was determined using the Bradford method (Protein Assay Dye Reagent, Bio-Rad, Hercules, CA). Equal amounts $(50 \mu \mathrm{g})$ of protein were loaded and separated on SDSPolyacrylamide gel (10\% acrylamide). Proteins were then transferred onto nitrocellulose membranes. Membranes were blocked in 5\% BSA in TBST (100 mL TBS 10X, $900 \mathrm{~mL}$ H2O, $1 \mathrm{~mL}$ Tween 20, Sigma Aldrich St Louis Mo) for one hour and afterward incubated with primary antibody (Ab Thermo Fisher, 1:500) overnight at $4^{\circ} \mathrm{C}$. The membranes were then treated with horseradish peroxidase-conjugated secondary antibody and developed using an enhanced chemiluminescence kit (Sigma Aldrich St Louis Mo).

\section{Immunofluorescence}

Immunofluorescence staining and confocal analysis. MGCs were seeded on coverslips. The cells were fixed with cold $4 \%$ paraformaldehyde for 15 minutes, permeabilized with $0.1 \%$ Triton X-100 for 10 minutes, blocked in 1\% BSA and 10\% normal donkey serum in PBS for 10 minutes, incubated with anti- 
DUOX2 antibody (Thermo Fisher) diluted 1:100 for 1 hour at room temperature, washed 3 times, stained with FITC-conjugated donkey anti-mouse antibody for 1 hour at room temperature, and washed again 6 times. The slides were mounted with coverslips using GelMount (Biomeda), and the cells were analyzed with a Leica SP5 (Leica) confocal laser scanning microscope.

\section{Superovulation protocol}

25-day old C57BL female mice were injected with $10 \mathrm{U}$ of Pregnant mare's serum gonadotropin (PMSG, Sigma, St. Louis, MO, USA) to stimulate follicle growth, and $48 \mathrm{~h}$ later with an ovulatory dose of $10 \mathrm{U}$ hCG that mimicking an endogenous LH surge, stimulating follicle development and ultimately ovulation 12$16 \mathrm{~h}$ later. The animals were sacrificed $48 \mathrm{~h}$ after PMSG treatment as well as 3, 6, 9, 12, 16 and 24 hours after hCG administration.

All mice were sacrificed by $\mathrm{CO}_{2}$ asphyxiation, and the ovaries were removed and either frozen or paraformaldehyde-fixed until used, or punctured to collect entrapped oocytes. Blood samples were collected at the time of euthanasia for progesterone measurement, and the number of oocytes within the ampullas of all oviducts was recorded.

DPI (Almog diagnostic 5 or $7 \mathrm{mg} / \mathrm{kg}$ ) was injected at the same time as hCG to PMSG-primed mice. Mice treated with hCG and vehicle (DMSO) served as controls. Mice were sacrificed 16 hours after the administration

\section{Mouse ovarian morphology}

Fixed ovaries ( $4 \%$ formalin) were embedded in paraffin blocks, mounted on slides, and stained with hematoxylin/eosin. Mouse ovarian morphology was assessed by examining $4-\mu \mathrm{m}$ serial histological sections cut by a microtome.

\section{Measurement of progesterone concentrations}

Blood samples for hormone assays in female mice were obtained at the time of euthanasia by cardiac puncture. Sera were separated from whole blood and frozen until the time of analysis. Progesterone concentrations were measured in duplicate by the American Medical Laboratories in Herzliya, Israel.

\section{$\mathrm{H}_{2} \mathrm{O}_{2}$ measurement}

MGCs aspirated during IVF procedures were cultured for 4 days with daily medium exchange (Medium 199 Sigma Aldrich St Louis Mo). MGCs were stimulated with hCG 1 U/ml. 15 hours after hCG administration, the medium was exchanged to DMEM medium (DMEM/F-12, no Phenol Red) $1 \%$ FBS (Invitrogen Grand Island, NY) and 1\% penicillin/streptomycin (Sigma Aldrich St Louis Mo). MGCs were stimulated either with vehicle (control), $1 \mathrm{U} / \mathrm{ml} \mathrm{hCG}$, with or without DPI inhibitor $10 \mu \mathrm{M}$. $\mathrm{CaCl}_{2} 1 \mathrm{mM}$ was added to all cells. 
Detection of $\mathrm{H}_{2} \mathrm{O}_{2}$ using the AmplexR Red Hydrogen Peroxide/Peroxidase Assay Kit (Invitrogen Catalog no. A22188). The reaction was started by adding a working solution of $100 \mu \mathrm{M}$ Amplex ${ }^{\circledR}$ Red reagent and $0.2 \mathrm{U} / \mathrm{mL}$ HRP to each microplate well containing the standards, controls, and samples. The plate was incubated for 1 hour at room temperature protected from light. Fluorescence was then measured with a fluorescence microplate reader. Fluorescence emission detection at $570 \mathrm{~nm}$. Background fluorescence, determined for a no-HRP control reaction, has been subtracted from each value.

\section{Statistics}

Each experiment was carried out at least three times. Data, expressed as mean $\pm \mathrm{SEM}$, were evaluated with Student's t-test (two-tailed) or with ANOVA for more than 2 variables using the post hoc Tukey test assuming equal variances or the Games-Howell test for unequal variances. When appropriate, KruskalWallis non-parametric comparison test was used. SPSS 20 software (IBM) was used for all analyses. P values $<0.05$ were considered statistically significant.

\section{Declarations}

\section{Ethics approval and consent to participate}

The study was approved by the local Institutional Review Board (IRB) committee of Chaim Sheba Medical Center, Tel Hashomer (ethical approval number SMC-11-8707 and SMC-12-9342). Written informed consent was obtained from each patient who provided samples. All experiments involving mice were conducted in compliance with the principles of the National Research Council (NRC) and were approved by the institutional animal care and use committee (IACUC) \#919/14/ANIM.

\section{Consent for publication}

Not applicable.

\section{Availability of data and materials}

The datasets generated and analyzed during the current study are available in the GEO repository, GSE50174. All other data generated or analyzed during this study are included in this published article.

\section{Competing interests}

The authors declare that they have no competing interests.

\section{Funding}

This study was supported by grants from the Ministry of Health, Israel (3-00000-7410 to A.H.), and from the Chaim Sheba Medical Center (R\&D Sheba grant 5/2014 to A.H.).

\section{Author contributions}


G.M.Y., Y.Y., O.S., E.M., S.A., A.K. and A.H. contributed to the study design and analysis, the interpretation of the data, and the writing of the manuscript. O.S. and Y.Y. were involved in sample preparation and in vivo and in vitro experimental work. All the authors have contributed to data analysis and to finalizing the manuscript.

\section{Acknowledgements}

Not applicable.

\section{References}

1. Bedard K, Krause KH. The NOX family of ROS-generating NADPH oxidases: physiology and pathophysiology. Physiological reviews. 2007;87(1):245-313.

2. Rada B, Leto TL. Oxidative innate immune defenses by Nox/Duox family NADPH oxidases. Contributions to microbiology. 2008;15:164-87.

3. Shkolnik K, Tadmor A, Ben-Dor S, Nevo N, Galiani D, Dekel N. Reactive oxygen species are indispensable in ovulation. Proceedings of the National Academy of Sciences of the United States of America. 2011;108(4):1462-7.

4. Carlson JC, Wu XM, Sawada M. Oxygen radicals and the control of ovarian corpus luteum function. Free radical biology \& medicine. 1993;14(1):79-84.

5. Agarwal A, Aponte-Mellado A, Premkumar BJ, Shaman A, Gupta S. The effects of oxidative stress on female reproduction: a review. Reproductive biology and endocrinology : RB\&E. 2012;10:49.

6. Devine PJ, Perreault SD, Luderer U. Roles of reactive oxygen species and antioxidants in ovarian toxicity. Biology of reproduction. 2012;86(2):27.

7. Yerushalmi GM, Markman S, Yung Y, Maman E, Aviel-Ronen S, Orvieto R, et al. The prostaglandin transporter (PGT) as a potential mediator of ovulation. Sci Transl Med. 2016;8(338):338ra68.

8. Yerushalmi GM, Salmon-Divon M, Yung Y, Maman E, Kedem A, Ophir L, et al. Characterization of the human cumulus cell transcriptome during final follicular maturation and ovulation. Mol Hum Reprod. 2014;20(8):719-35.

9. Ameziane-El-Hassani R, Morand S, Boucher JL, Frapart YM, Apostolou D, Agnandji D, et al. Dual oxidase-2 has an intrinsic Ca2+-dependent H2O2-generating activity. The Journal of biological chemistry. 2005;280(34):30046-54.

10. Khamsi F, Roberge S. Granulosa cells of the cumulus oophorus are different from mural granulosa cells in their response to gonadotrophins and IGF-I. J Endocrinol 2001;170(3):565-73.

11. Cross PC, Brinster RL. In vitro development of mouse oocytes. Biology of reproduction. 1970;3(3):298-307.

12. Goud PT, Goud AP, Qian C, Laverge H, Van der Elst J, De Sutter P, et al. In-vitro maturation of human germinal vesicle stage oocytes: role of cumulus cells and epidermal growth factor in the culture medium. Hum Reprod. 1998;13(6):1638-44. 
13. Assou S, Haouzi D, Mahmoud K, Aouacheria A, Guillemin Y, Pantesco V, et al. A non-invasive test for assessing embryo potential by gene expression profiles of human cumulus cells: a proof of concept study. Molecular human reproduction. 2008;14(12):711-9.

14. Uyar A, Torrealday S, Seli E. Cumulus and granulosa cell markers of oocyte and embryo quality. Fertility and sterility. 2013;99(4):979-97.

15. Ophir L, Yung Y, Maman E, Rubinstein N, Yerushalmi GM, Haas J, et al. Establishment and validation of a model for non-luteinized human mural granulosa cell culture. Mol Cell Endocrinol. 2014;384(12):165-74.

16. Gudermann T, Birnbaumer M, Birnbaumer L. Evidence for dual coupling of the murine luteinizing hormone receptor to adenylyl cyclase and phosphoinositide breakdown and Ca2+ mobilization. Studies with the cloned murine luteinizing hormone receptor expressed in $L$ cells. The Journal of biological chemistry. 1992;267(7):4479-88.

17. Morris JK, Richards JS. Luteinizing hormone induces prostaglandin endoperoxide synthase-2 and luteinization in vitro by A-kinase and C-kinase pathways. Endocrinology. 1995;136(4):1549-58.

18. Conti M, Hsieh M, Park JY, Su YQ. Role of the epidermal growth factor network in ovarian follicles. Molecular endocrinology (Baltimore, Md). 2006;20(4):715-23.

19. Su YQ, Sugiura K, Li Q, Wigglesworth K, Matzuk MM, Eppig JJ. Mouse oocytes enable LH-induced maturation of the cumulus-oocyte complex via promoting EGF receptor-dependent signaling. Mol Endocrinol. 2010;24(6):1230-9.

20. Kim J, Bagchi IC, Bagchi MK. Control of ovulation in mice by progesterone receptor-regulated gene networks. Molecular human reproduction. 2009;15(12):821-8.

21. Fulop C, Szanto S, Mukhopadhyay D, Bardos T, Kamath RV, Rugg MS, et al. Impaired cumulus mucification and female sterility in tumor necrosis factor-induced protein- 6 deficient mice. Development. 2003;130(10):2253-61.

22. Kohen P, Castro O, Palomino A, Muñoz A, Christenson LK, Sierralta W, et al. The steroidogenic response and corpus luteum expression of the steroidogenic acute regulatory protein after human chorionic gonadotropin administration at different times in the human luteal phase. The Journal of clinical endocrinology and metabolism. 2003;88(7):3421-30.

23. Sirokmany G, Donko A, Geiszt M. Nox/Duox Family of NADPH Oxidases: Lessons from Knockout Mouse Models. Trends Pharmacol Sci. 2016;37(4):318-27.

24. De Deken X, Wang D, Many MC, Costagliola S, Libert F, Vassart G, et al. Cloning of two human thyroid cDNAs encoding new members of the NADPH oxidase family. The Journal of biological chemistry. 2000;275(30):23227-33.

25. Dupuy C, Ohayon R, Valent A, Noel-Hudson MS, Deme D, Virion A. Purification of a novel flavoprotein involved in the thyroid NADPH oxidase. Cloning of the porcine and human cdnas. The Journal of biological chemistry. 1999;274(52):37265-9.

26. Rigutto S, Hoste C, Grasberger H, Milenkovic M, Communi D, Dumont JE, et al. Activation of dual oxidases Duox1 and Duox2: differential regulation mediated by camp-dependent protein kinase and 
protein kinase C-dependent phosphorylation. The Journal of biological chemistry. 2009;284(11):6725-34.

27. Buck T, Hack CT, Berg D, Berg U, Kunz L. The NADPH oxidase 4 is a major source of hydrogen peroxide in human granulosa-lutein and granulosa tumor cells. 2019;9(1):3585.

28. Ophir L, Yung Y, Yerushalmi GM, Baum M, Machtinger R, Maman E, et al. An optimized model for hCG stimulation of human mural granulosa cell culture. Reproductive biology. 2019;19(1):67-74.

\section{Figures}

Fig. 1
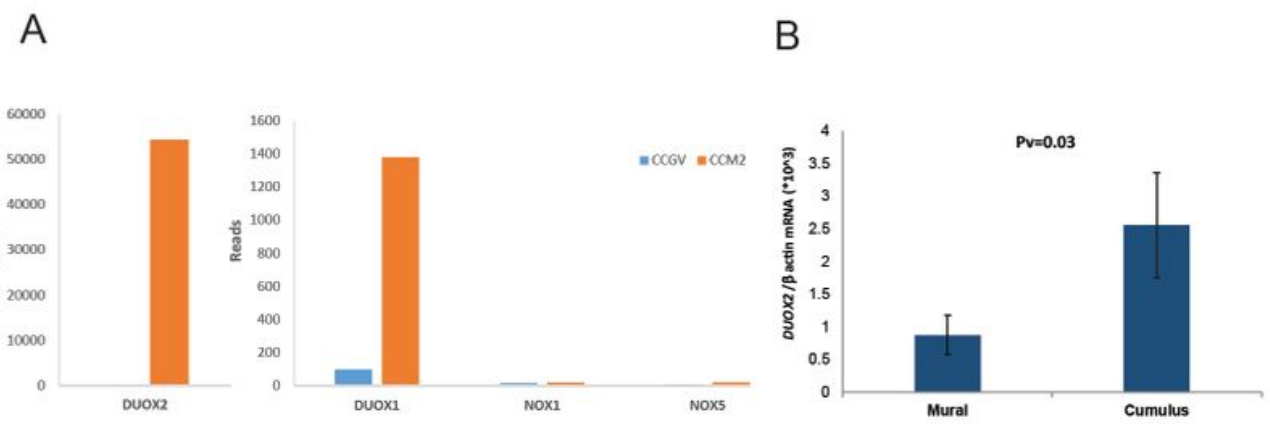

C

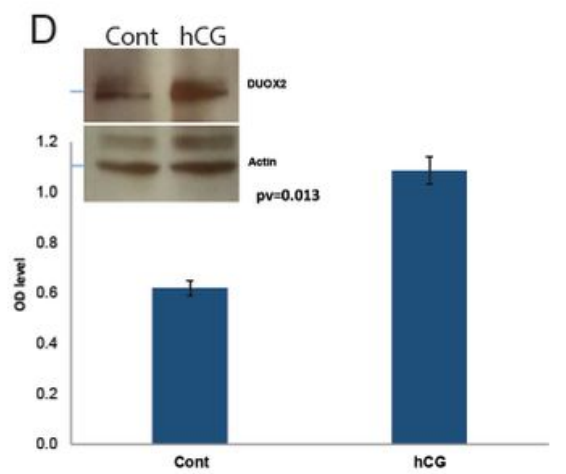

E

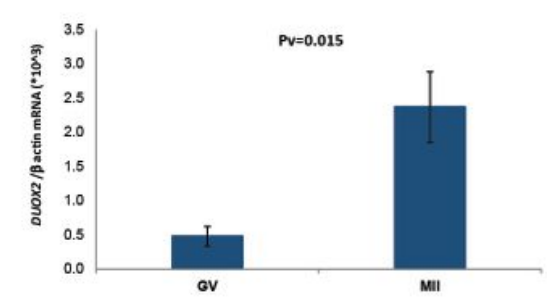

$\mathrm{F}$

G
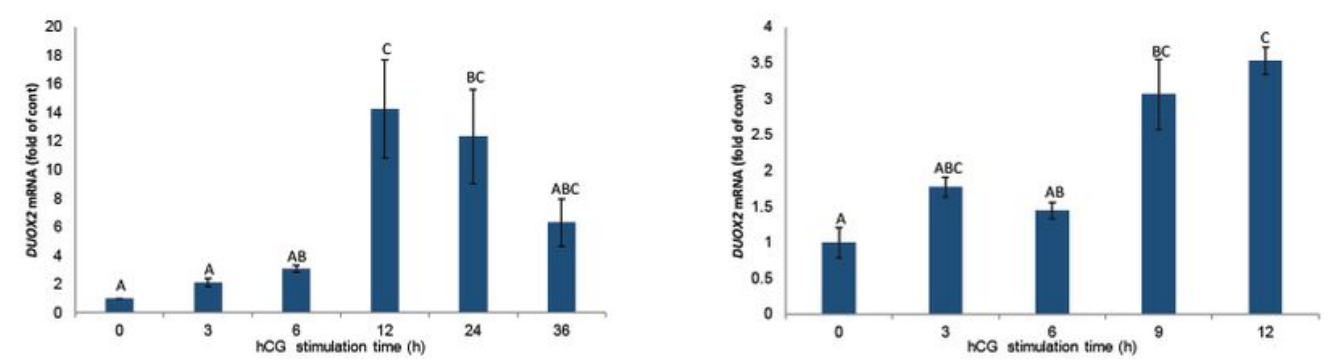

Figure 1

DUOX2 expression pattern. (A) RNAseq expression (reads) of DUOX2 in the CGCs surrounding a GV oocyte after IVM treatment and in expanded CGCs surrounding MII oocytes. Global transcriptome sequencing was performed on CCM2 samples obtained from three women and CCGV samples obtained from two women as described previously (8) (B) CGCs and MGCs aspirated from preovulatory follicles 
$(>17 \mathrm{~mm}$ ) during IVF procedures. DUOX2 was quantified by qPCR and normalized to $\beta$-actin expression. Data represent the mean \pm SEM of four independent experiments. (C) CCs were denuded from COCs aspirated from preovulatory follicles $(>17 \mathrm{~mm})$ during IVF procedures. CCs from each COC were assigned according to the maturation state of the oocyte. Each sample includes CCs from 3-4 COCs. DUOX2 was quantified by qPCR and normalized to $\beta$-actin expression. Data represent the mean \pm SEM of four independent experiments. (D) MGCs aspirated from preovulatory follicles ( $>17 \mathrm{~mm}$ ) during IVF procedures and cultured for 3-4 days. MGCs were stimulated with vehicle (control) or hCG $(1 \mathrm{U} / \mathrm{ml})$ for 24 hours. Protein levels of DUOX2 expression were determined by western blotting. Each sample included pooled cells from 2 to 4 COCs. $\beta$-actin was used as a control. A representative blot is present. Quantification of three western blots using image $\mathrm{j}$ software. Results are expressed as mean \pm SEM of three independent experiments. (E) MGCs were stimulated with vehicle (control) or hCG (1U/ml) for 24 hours. Protein levels of DUOX2 expression were determined by immunofluorescence. DUOX2 expression pattern during the ovulatory interval. $(F)$ in vitro. MGCs aspirated from preovulatory follicles $(>17 \mathrm{~mm}$ ) during IVF procedures, and cultured for 3-4 days. MGCs were stimulated with vehicle (control) or hCG $(1 \mathrm{U} / \mathrm{ml})$ and harvested at 3, 6, 12, 24 and $36 \mathrm{~h}$ after $\mathrm{hCG}$ administration. The cells were subjected to total RNA extraction. (G) in vivo. 25-day old female mice were injected with saline or 10U PMSG to stimulate follicle growth, and 48 hours later with an ovulatory dose of $10 \mathrm{U} \mathrm{hCG}$ to induce ovulation. The mice were sacrificed 48 hours after PMSG and saline treatment and 3, 6, 9, 12 hours after hCG treatment. The ovaries were collected and the total ovarian RNA was extracted. DUOX2 mRNA expression was assessed by qPCR and calculated relative to the $\beta$-actin level in the same sample. The results are expressed as the mean $\pm S E M$ of three independent experiments. Different letters represent significant differences $(P<0.05$, One-way ANOVA test). 


\section{Fig. 2}
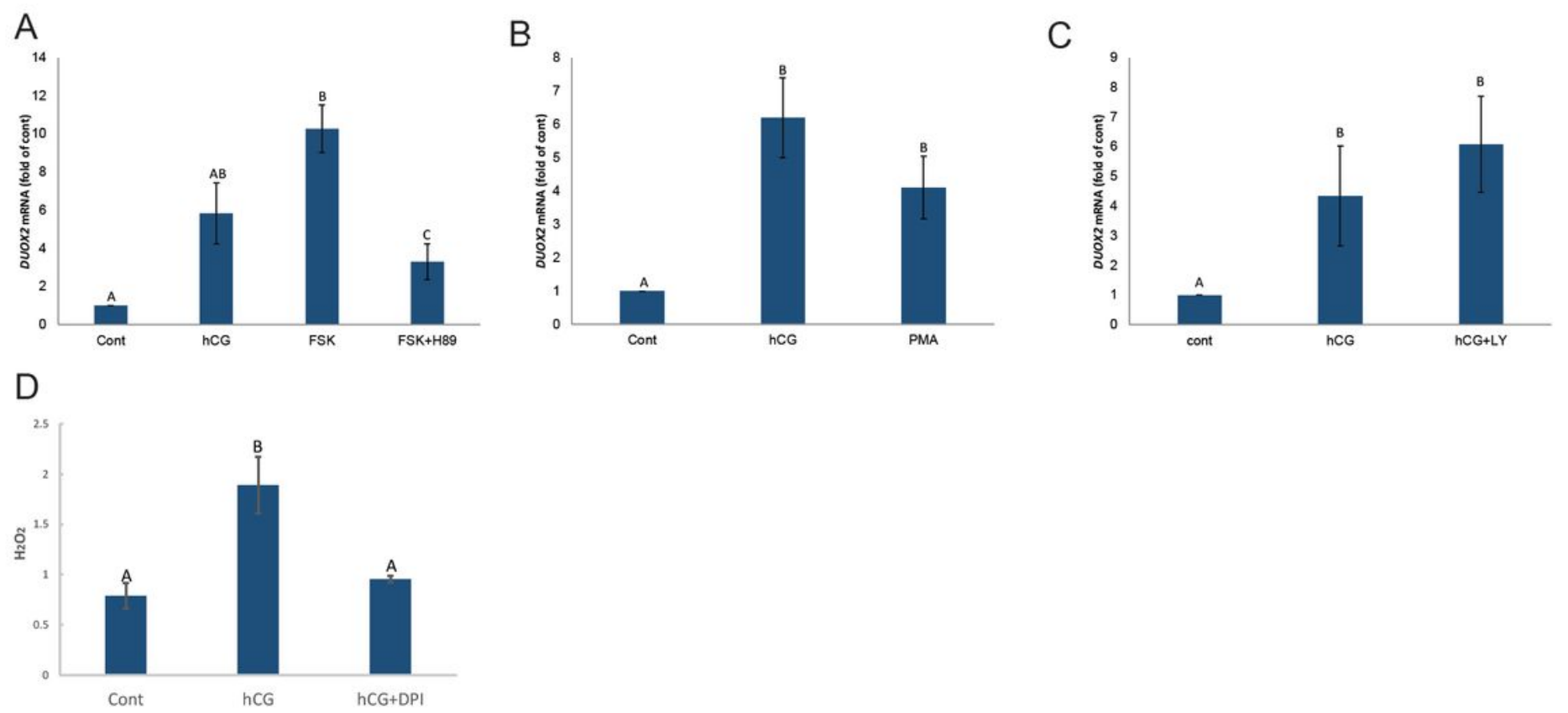

Figure 2

Signaling pathways regulation of LH- induced expression of DUOX2 mRNA. MGCs aspirated during IVF procedures were cultured for 4 days with daily medium exchanges. MGCs were either stimulated with (A) MGCs were either left untreated (control), or stimulated with hCG $1 \mathrm{U} / \mathrm{ml}$ (hCG), or forskolin $10 \mu \mathrm{M}$ (FSK), or a combination of forskolin $10 \mu \mathrm{M}$ and H89 $10 \mu \mathrm{M}$ (H89) for 24h. (B) left untreated (control), hCG 1 $\mathrm{U} / \mathrm{ml}$ or $20 \mathrm{nM}$ PMA (C) left untreated (control), stimulated with hCG $1 \mathrm{U} / \mathrm{ml}$ (hCG) or a combination of hCG $1 \mathrm{U} / \mathrm{ml}$ with LY $29400210 \mu \mathrm{M}$ (hCG+LY) for 24h. mRNA levels of DUOX2 were analyzed by qPCR. DUOX2 expression was calculated relative to the $\beta$-actin level in the same sample. The results are expressed as fold change with respect to control that was set to 1 . The results are expressed as the mean \pm SEM of three to six independent experiments. Different letters represent significant differences. $(P<$ 0.05, One-way ANOVA test). (D) The role of DUOX2 in hCG induced H2O2 generation. MGCs aspirated during IVF procedures were initially cultured for 4 days and then stimulated with $\mathrm{FSH}(1 \mathrm{U} / \mathrm{ml})$ for 48 hours. FSH-pretreated MGCs were then exposed to hCG $(1 \mathrm{U} / \mathrm{ml})$ for 15 hours to induce DUOX2 protein.

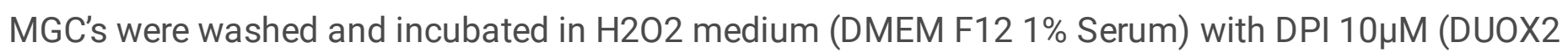
inhibitor) or left untreated (control) for $10 \mathrm{~h}$. The $\mathrm{H} 2 \mathrm{O} 2$ levels in the medium were quantified using the Amplex® Red Hydrogen Peroxide/Peroxidase Assay Kit. The results are expressed as mean \pm SEM of four independent experiments. 
Fig. 3

A
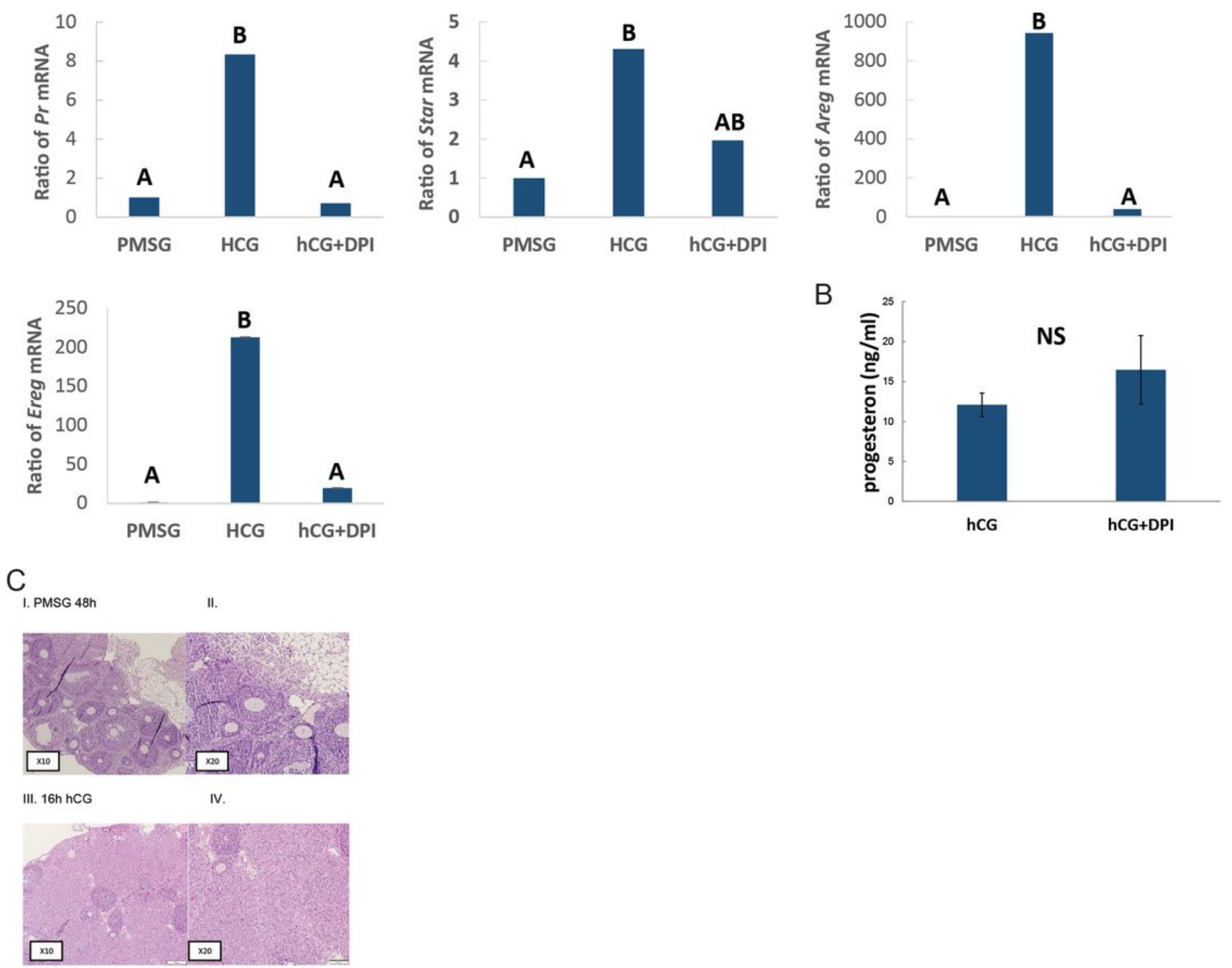

V. $16 \mathrm{hhCG}+\mathrm{DPI}$

VI.

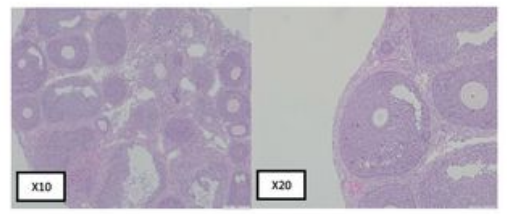

\section{Figure 3}

The effect of DPI on the expression of LH/hCG target genes, serum progesterone concentration, and ovarian histology. (A) 25-day-old female mice were superovulated with 10U PMSG for 48h, followed by injection of $10 \mathrm{U} / \mathrm{ml} \mathrm{hCG}$ with or without the $7 \mathrm{mg} / \mathrm{kg}$ DPI. Animals were sacrificed 3 hours after hCG administration. The ovaries were collected, and the RNA was extracted. mRNA levels of each gene were assessed by qPCR and expressed relative to $\beta$-actin mRNA in each sample. The results are expressed as the mean \pm SEM of three independent experiments. Expression of LH/hCG target genes: Areg, Ereg, Tnfaip6, Pr and Star. The results are expressed as the mean \pm SEM of three mice per group. Different 
letters represent significant differences ( $P<0.05$, One-way ANOVA test). (B) Serum progesterone concentration in $\mathrm{hCG}$ treated ovaries compares to $\mathrm{hCG}$ and DPI treated ovaries. For progesterone concentration, the animals were sacrificed 24 hours after $\mathrm{hCG}$ administration. The results are expressed as the mean $\pm S E M$ of three mice per group. "NS" indicates not significant $(P<0.05$, two-tailed t-test). (C) The effect of DPI on ovarian histology. 25-day-old female mice were injected with 10U PMSG for 48h to induce follicle growth, followed by $10 \mathrm{U} \mathrm{hCG}$ or $10 \mathrm{U} \mathrm{hCG}$ and $7 \mathrm{mg} / \mathrm{kg} \mathrm{DPI}$ for $16 \mathrm{~h}$. The ovaries were fixed in $4 \%$ formaldehyde. Paraffin-embedded sections were serially sectioned and stained with hematoxylin and eosin and examined by light microscopy. Representative images are displayed: (I) 48h after treatment with PMSG. (II) Higher magnification of a portion of the PMSG-primed ovary at the 48-hour time point. (III) $16 \mathrm{~h}$ after the administration of hCG. (IV) Higher magnification of one postovulatory follicle forming an early corpus luteum. (V) $16 \mathrm{~h}$ after the administration of hCG + DPI. (VI) Higher magnification of the ovary $16 \mathrm{~h}$ after the administration of hCG + DPI.

\section{Supplementary Files}

This is a list of supplementary files associated with this preprint. Click to download.

- Supplementarydata.docx 